\section{Pulsed radiofrequency therapy might be not inferior to ther- mal neurotomy in lumbar facet joint pain: a commentary}

\author{
Haiko Sprott, Norina Bergamin, Armin \\ Aeschbach \\ University of Zürich, Switzerland
}

\begin{abstract}
The effects of pulsed radiofrequency treatment in low back pain was evaluated in a routine clinical setting and compared with thermal neurotomy of nerve structures of the facet joint. The treatment of 19 patients with lumbar facet joint pain was prospectively evaluated. Follow-ups were recorded at 6 weeks and 6 months after intervention. Patients with $\geq 50 \%$ pain relief following controlled diagnostic local anesthetic block underwent medial branch neurotomy with thermal continuous radiofrequency (CRF, $\mathrm{n}=16$ ) or pulsed radiofrequency (PRF, $n=3$ ). Experiences between the two radiofrequency modes in the treatment of facet joint pain were recorded. In the overall population, a facet joint pain reduction of $23 \%$ at 6 weeks, $20 \%$ at 6 months and an improvement in various clinical scores was achieved. CRF and PRF appeared to be similarly effective in the treatment of facet joint pain, providing pain relief for at least 6 months. These observations should encourage pain researcher to design meaningful studies to further address this concept.
\end{abstract}

\section{Introduction}

Percutaneous radiofrequency procedures have become a frequently performed treatment option in the management of chronic pain. It is well established in the treatment of back pain of facet joint origin and was increasingly introduced in the treatment of various other chronic pain conditions. ${ }^{1}$ The use of pulsed radiofrequency (PRF) in chronic pain conditions has never been validated.

There are two basic types of radiofrequency. The thermal, or so-called continuous radiofrequency (CRF) produces a well-circumscribed heat lesion in the target tissue. It is confirmed as a safe and atraumatic procedure with a low complication rate. ${ }^{2}$ However, the fact that the high temperature around the electrode might coagulate the nerve, implicates a strong indication within the management of neuropathic pain syndromes by CRF. ${ }^{3}$
With the development of PRF, ${ }^{4}$ a nondestructive radiofrequency method became available. ${ }^{5}$ In contrast to CRF the RF-current is delivered in short pulses. The silent phase between the bursts allows the heat to dissipate in order to keep the heat at the electrode tip below the neurodestructive temperature of $43^{\circ} \mathrm{C} .{ }^{6}$ Since PRF proved to be safe and is in addition easier to perform than CRF, it was very quickly introduced in clinical practice. Nevertheless, the research about the biological effects is considerably lagging behind ${ }^{3,6}$ and the mechanisms responsible for the analgesic effect of PRF are still not completely understood. The electromagnetic fields induced by the RF-current are believed to play an important role having an impact on cell morphology, synaptic transmission and pain signaling which may account for the pain relief. ${ }^{7}$

We want to collect arguments to show the non-inferiority of PRF compared to CRF in the treatment for lumbar facet joint pain. It is estimated as the cause in about 15 to $45 \%$ of the patients with chronic low back pain ${ }^{8}$ and is mostly associated with degenerative processes of the spinal column. ${ }^{9} \mathrm{CRF}$ therapy seems to be a promising treatment. Some randomized controlled trials (RCT) however, showed inconsistent evidence. ${ }^{10,11}$ They failed to clarify the efficacy due to some methodological and technical flaws. ${ }^{11}$ More convincing results are available from studies that use accurate technique and diagnostic criteria. In the newest RCT up to date, the treatment effect of CRF was significantly superior to sham-treatment at 6 months. ${ }^{12}$ In well-designed prospective studies, between 50 and $90 \%$ of pain relief could be achieved over all in at least $50 \%$ of the patients, generally lasting between 6 and 12 months. ${ }^{13-15}$ In order to reduce the heat related side effects and to shorten the time-consuming CRF-procedure, there have been some attempts to apply PRF instead of CRF to the medial branch. ${ }^{7}$ The RCT's comparing the outcomes of the two RF-methods concluded that PRF has a comparable short-term outcome to CRF, but that the effect of the latter lasts longer. ${ }^{16,17}$ Therefore, we examined prospectively patients with chronic low back pain who did not respond to conservative management.

\section{Materials and Methods}

The inclusion criteria for the patients with facet joint pain consisted in a positive diagnosis of facet joint pain with controlled diagnostic local anesthetic blocks.

Written informed consent was obtained from all patients and the study was approved by the ethical review board of the University of Zurich. A total of 19 patients were recruited at the University Hospital of Zurich, Division of
Correspondence: Haiko Sprott, University of Zürich, Arztpraxis Hottingen, Hottingerstrasse 44, CH-8032 Zürich, Switzerland.

Tel.: +41.044.577.40.10 - Fax: +41.044.577.40.09. E-mail: praxis.prof.sprott@hin.ch

Key words: Pulsed radiofrequency; thermal radiofrequency; neurolysis; low back pain; facet joint.

Acknowledgments: the authors wish to thank Mrs. Diana Haag for the grammatical correction of the manuscript.

Contributions: HS designed the investigation, performed the physical examinations of the patients, carried out the interventions, and wrote the manuscript; NB analyzed the data and helped writing the manuscript; AA supervised the interventions, discussed the data, and edited the manuscript.

Conflict of interest: the authors declare no potential conflict of interest.

Received for publication: 13 November 2015 .

Revision received: 23 November 2015.

Accepted for publication: 1 December 2015.

This work is licensed under a Creative Commons Attribution NonCommercial 4.0 License (CC BYNC 4.0).

(C) Copyright H. Sprott et al., 2016

Licensee PAGEPress, Italy

Rheumatology Reports 2016; 8:6167

doi:10.4081/rr.2016.6167

Rheumatology and included in the study. The last 3 patients of the group were treated with PRF as part of a pilot observational assessment.

The procedures were performed following the recommendations of the International Spine Intervention Society.

The blocks were performed under aseptic conditions, fluoroscopic guidance and local skin anesthesia without sedation. The radiofrequency procedures were performed in a similar manner under local anesthesia at the same nerves as the diagnostic blocks. For CRF treatment, a $22 \mathrm{G}$ spinal needle was inserted parallel to the course of the medial branch at the angle between the superior articular and the transverse process with the $\mathrm{C}$-arm intensifier in an approximately $20^{\circ}$ oblique position. In lateral view the needle tip was positioned in the middle to anterior third line of the groove. For L5 branch the target point was the junction between the ala and the superior articular process of the sacrum. Correct and extra vascular needle placement was verified with 
antero-posterior, lateral and oblique fluoroscopic views. A small amount of lidocaine 1\% and triamcinolon was injected to prevent thermal pain and postinterventional neuritis. A TCU 415 TC-Electrode with $10 \mathrm{~mm}$ active tip was inserted and connected to a RF-generator. Electrical stimulation at 2 and $50 \mathrm{~Hz}$ was performed to exclude the proximity to other nervous structures. Subsequently two thermal lesions at $80^{\circ} \mathrm{C}$ for $90 \mathrm{~s}$ were produced at slightly different positions along the nerve using a RF-generator. ${ }^{18}$

In the PRF group the electrode with a $2 \mathrm{~mm}$ active tip was placed at the same target points, but with the tip positioned perpendicular to the nerve. RF-current (max. 45V) at $2 \mathrm{~Hz}$ with a pulse duration of $20 \mathrm{~ms}$ was applied twice for 2 minutes with slightly changed positions and an electrode tip temperature of maximal $42^{\circ} \mathrm{C} .6,19$ The patients filled in a questionnaire before treatment, six weeks after and six months after the intervention. The questionnaire contained 11-point numeric rating scales (NRS) to record different pain parameters (present pain, highest and lowest pain intensity during the last week, average pain during the last week $) \quad(0=$ not at all/never, $10=$ worst/always), improvement in the quality of life $(0=$ no improvement, $10=$ max improvement), and the satisfaction with the procedure ( 0 =unsatisfied; $10=$ completely satisfied).

Quantity of low back pain, quality of life, and the impairment of different daily activities (to get dressed, uplifting something, running and walking, sitting, standing, sleeping, travelling, social life and leisure time) were documented with a 6 -point NRS $(0=$ not at all/never, $5=$ worst/always). Quality of low back pain was interviewed also with a 6 -point NRS $(0=$ no pain at all, $5=$ most penetrating). Prior to the procedure the desired pain relief could be noted in percentages. All patients noted their analgesic intake before and after treatment, which was recorded by the 3 steps of the World

Table 1. Demographic and clinical data of the included patients at baseline.

\begin{tabular}{lc} 
Feature & $\mathbf{N}$. \\
Patients & 19 \\
Males (\%) & $7(37)$ \\
\hline Females (\%) & $12(63)$ \\
Age, years, mean $( \pm$ SD) & $54( \pm 13)$ \\
\hline Employed (\%) & $12(63)$ \\
Part time employment per month $( \pm$ SD) & $33( \pm 37)$ \\
\hline Unemployed (\%) & $7(39)$ \\
Work characteristics (\%) & \\
$\quad$ Retired & $4(19)$ \\
$\quad$ Sedentary & $4(19)$ \\
$\quad$ Standing & $11(62)$ \\
\hline Painful movement $( \pm$ SD) & \\
Sitting & $69( \pm 48)$ \\
Standing & $75( \pm 45)$ \\
Walking & $69( \pm 48)$ \\
Carrying/picking something up & $69( \pm 48)$ \\
Sports/leisure time & $88( \pm 34)$ \\
Working & $81( \pm 40)$ \\
\hline
\end{tabular}

SD, standard deviation.

Table 2. Data of the patients with facet joint pain. Mean pre-procedural and post-procedural values.

\begin{tabular}{|c|c|c|c|c|c|}
\hline \multirow[t]{2}{*}{ Measures } & \multirow[t]{2}{*}{ Pretreat $(\mathrm{n}=19)$} & \multicolumn{3}{|c|}{ Scores (mean) } & \multirow[b]{2}{*}{ Diff to pre } \\
\hline & & 6 weeks ( $n=16$ ) & Diff to pre & 6 months $(n=13)$ & \\
\hline Present pain & 6.7 & 4.4 & -2.3 & 4.6 & -2.1 \\
\hline Heaviest pain-intensity & 8.1 & 6.6 & -1.5 & 6.2 & -1.9 \\
\hline Lowest pain-intensity & 4.4 & +2 & -1.3 & 3.1 & -1.3 \\
\hline Average pain-intensity & 5.9 & 4.5 & -1.4 & 4.8 & -1.1 \\
\hline Quality of life & 4.5 & 5.3 & +0.8 & 5.3 & +0.8 \\
\hline $\begin{array}{l}\text { Quantity of } \\
\text { low-back pain } \\
\text { pain in the leg }\end{array}$ & $\begin{array}{l}5.1 \\
2.8\end{array}$ & $\begin{array}{l}3.9 \\
2.3\end{array}$ & $\begin{array}{l}-1.2 \\
-0.5\end{array}$ & $\begin{array}{l}3.6 \\
2.5\end{array}$ & $\begin{array}{l}-1.5 \\
-0.3\end{array}$ \\
\hline \multicolumn{6}{|l|}{ Quality of } \\
\hline low-back pain & 4.8 & 3.4 & -1.4 & 3.0 & -1.8 \\
\hline pain in the leg & 2.8 & 2.4 & -0.4 & 2.3 & -0.5 \\
\hline $\begin{array}{l}\text { Impairment of } \\
\text { getting dressed } \\
\text { uplifting something } \\
\text { running and walking } \\
\text { sitting } \\
\text { standing } \\
\text { sleeping } \\
\text { social life and leisure time } \\
\text { travelling }\end{array}$ & $\begin{array}{l}3.0 \\
4.0 \\
3.0 \\
2.8 \\
3.8 \\
3.6 \\
3.7 \\
2.8\end{array}$ & $\begin{array}{l}2.3 \\
4.1 \\
2.2 \\
2.4 \\
2.8 \\
2.5 \\
2.8 \\
2.1\end{array}$ & $\begin{array}{l}-0.7 \\
+0.1 \\
-0.8 \\
-0.4 \\
-1.0 \\
-1.1 \\
-0.9 \\
-0.7\end{array}$ & $\begin{array}{l}2.5 \\
3.9 \\
2.3 \\
2.1 \\
2.9 \\
3.3 \\
3.1 \\
2.5\end{array}$ & $\begin{array}{l}-0.5 \\
-0.1 \\
-0.7 \\
-0.7 \\
-0.9 \\
-0.3 \\
-0.6 \\
-0.3\end{array}$ \\
\hline Analgesics & 1.3 & 1.3 & 0 & 1.5 & +0.2 \\
\hline Satisfaction & & 5.1 & & 6.5 & \\
\hline Feeling depressed & & 1.4 & & 1.5 & \\
\hline Average pain relief (\%) & & 23.3 & & 19.9 & \\
\hline
\end{tabular}


Health Organization-ladder $(0=$ no analgesics, $1=$ non-opioids, $2=$ =non-opioids + weak opioids, $3=$ non-opioids + strong opioids). The general emotional state was also detected by a 4-point scale: $0=$ feeling not at all depressed, $4=$ feeling very depressed) during the follow-up.

Differences in the treatment effects between PRF and CRF were assessed on the basis of average pain, heaviest pain, quality of life, mean pain reduction in percentage).

\section{Results}

Out of 19 patients (Table 1) treated for facet joint pain, 16 remained for the 6 week- and 13 patients for the 6 months follow-up. The 3 patients missing the 6 weeks-evaluation did only complete the questionnaire at 6 month. However 6 other patients did not participate in the 6-months follow-up. The results are given in Table 2. All pain parameters (present-, highest-, lowest and average pain) were reduced at 6 weeks, whereas at 6 months only the reduction in present and highest pain intensity appeared to be still improved. The effect decreased slightly at 6 months, except for the heaviest pain intensity that was even more released. Quality and quantity of low back pain was relieved during the whole follow-up and the relief was more distinct at 6 months. The quality of life showed only a slight improvement. The impairment of daily activities was improving during the whole follow-up for standing and sleeping and until 6 weeks for running/walking, social life/leisure time and travelling. All the other activities did not show any improvement. The patients' need for analgesics was not lower after the treatment. The patients felt a little to moderately depressed. The desired pain relief prior to procedure was $62 \%$ compared to an average relief of 23 and $20 \%$ at 6 weeks and 6 months. The satisfaction with the treatment ranged between 5.1 and 6.5 during the follow-up. No evidence for an increased efficacy of CRF compared to PRF was obtained in the studied population (Table 3 ). With regard to all evaluated parameters (average pain, heaviest pain, quality of life, pain reduction in percentage) the treatment effect was even more pronounced in the PRF group.

\section{Discussion and Conclusions}

As for PRF treatment for lumbar facet joint pain, the literature available to date is not sufficient to clarify the effectiveness, but indicates that it might be less efficient than CRF. In a prospective trial the average pain relief was at least $50 \%$ for an average duration of 4 months. ${ }^{20}$

It is known that the pain returns when the nerve regenerates, typically between 6 and 12 months with CRF neurotomy. ${ }^{12,14,15}$ Due to the non-destructive nature of PRF it seems natural that the nervous tissue regenerates more easily. Furthermore, some authors suspect that CRF is more effective because, in contrast to PRF, it temporarily and partially denervates the multifidus muscle and therefore eliminates a muscular component of back pain. . $^{16,20}$

In this observation, there have been no obviously differences between the CRF and PRF treated patients during the follow-up of 6 months, which suggests a comparable efficacy in our population. Surprisingly, the treatment effect was slightly more pronounced with the PRF application. The present results must be regarded as anecdotal due to the very small size of the PRF treated group. Nevertheless, they indicate that PRF might achieve a similar pain release as CRF in individual cases for at least 6 months.

The exact mechanisms responsible for the clinical effects of PRF are not yet completely understood. The low electric fields seem to play an important role in neuromodulation and alterations in synaptic transmission. On the one hand, they might induce a long-term depression of the synaptic transmission in the spinal cord that antagonizes the long-term potentiation influencing the processing of sensory information in chronic pain states. On the other hand, they seem to have an impact on different transcription factors in the neurons. ${ }^{7}$ These findings are reflected in trials where PRF could significantly relieve artificially induced neuropathic pain when applied to the DRG or peripheral nerves. ${ }^{20}$ Interestingly, in one of the studies the analgesic effect could be attenuated by the intrathecal application of antiadrenergic drugs. Descending noradrenergic and serotonergic inhibitory pathways are known to be involved in mediating endogenous analgesia. Thus, PRF possibly exerts a part of its analgesic effectiveness through an enhancement of those pathways. ${ }^{20}$ If and in what ways these findings might play a role in the clinical effect of PRF still needs to be established.

It can still be affirmed that radiofrequency denervation of the lumbar medial branches is an effective treatment option in lumbar facet joint pain. It provides significant pain relief for at least 6 months and an improvement in quality of life for at least 6 weeks to patients suffering for a long time from low back pain resistant to conservative management. Similar results can be achieved with PRF treatment in individual cases, which suggest an equal efficacy with higher safety. Therefore, non-destructive PRF might be useful alternative to CRF in these patients. However, due to the low number of treated PRF patients it will be not possible to draw final conclusions about the value of this method, but these observations should encourage both clinicians as well as pain researcher to design meaningful studies to proof this concept. The present results have to be understood in this context.

Table 3. Differences between continuous radiofrequency and pulsed radiofrequency treatment of the lumbar medial branch for facet joint pain.

\begin{tabular}{|c|c|c|c|c|}
\hline \multirow[t]{2}{*}{ Procedures/time points } & \multicolumn{3}{|c|}{ Scores (mean) } & \multirow[b]{2}{*}{ Quality of life } \\
\hline & Average pain & Heaviest pain & Average pain relief, \% & \\
\hline \multicolumn{5}{|l|}{ Pretreat } \\
\hline $\operatorname{PRF}(\mathrm{n}=3)$ & 7.0 & 8.7 & & 3.3 \\
\hline $\mathrm{CRF}(\mathrm{n}=16)$ & 5.8 & 8.0 & & 4.5 \\
\hline \multicolumn{5}{|l|}{6 weeks } \\
\hline PRF $(n=2)$ & 3.5 & 6.0 & 41.7 & 7.5 \\
\hline $\mathrm{CRF}(\mathrm{n}=14)$ & 4.6 & 6.7 & 20.7 & 4.9 \\
\hline \multicolumn{5}{|l|}{6 months } \\
\hline $\operatorname{PRF}(\mathrm{n}=3)$ & 3.7 & 5.0 & 42.6 & 7.0 \\
\hline $\mathrm{CRF}(\mathrm{n}=10)$ & 5.1 & 6.6 & 13.1 & 4.8 \\
\hline
\end{tabular}

CRF, continuous radiofrequency; PRF, pulsed radiofrequency. 


\section{References}

1. Manjunath PS, Jayalakshmi TS, Dureja GP, Prevost AT. Management of lower limb complex regional pain syndrome type 1 : an evaluation of percutaneous radiofrequency thermal lumbar sympathectomy versus phenol lumbar sympathetic neurolysis - a pilot study. Anesth Analg 2008;106:647-9.

2. Kornick C, Kramarich SS, Lamer TJ, et al. Complications of lumbar facet radiofrequency denervation. Spine 2004;29:1352-4.

3. Cohen SP, Van Zundert J. Pulsed radiofrequency: rebel without cause. Reg Anesth Pain Med 2010;35:8-10.

4. Sluijter M, Cosman E, Rittman I, van Kleef M. The effects of pulsed radiofrequency field applied to the dorsal root ganglion - a preliminary report. Pain Clin 1998;11:10917.

5. Munglani R. The longer term effect of pulsed radiofrequency for neuropathic pain. Pain 1999;80:437-9.

6. Bogduk N. Pulsed radiofrequency. Pain Med 2006;7:396-407.

7. Chua NH, Vissers KC, Sluijter ME. Pulsed radiofrequency treatment in interventional pain management: mechanisms and potential indications - a review. Acta Neurochir (Wien) 2011;153:763-71.
8. Sehgal N, Dunbar EE, Shah RV, Colson J. Systematic review of diagnostic utility of facet (zygapophysial) joint injections in chronic spinal pain: an update. Pain Physician 2007;10:213-28.

9. Cohen SP, Raja SN. Pathogenesis, diagnosis, and treatment of lumbar zygapophysial (facet) joint pain. Anesthesiology 2007;106:591-614.

10. Van Wijk RM, Geurts JW, Wynne HJ, et al. Radiofrequency denervation of lumbar facet joints in the treatment of chronic low back pain: a randomized, double-blind, sham lesion-controlled trial. Clin J Pain 2005;21:335-44.

11. Gofeld M, Faclier G. Radiofrequency denervation of the lumbar zygapophysial joints targeting the best practice. Pain Med 2008;9:204-11.

12. Nath S, Nath CA, Pettersson K. Percutaneous lumbar zygapophysial (facet) joint neurotomy using radiofrequency current, in the management of chronic low back pain: a randomized double-blind trial. Spine 2008;33:1291-8.

13. Speldewinde GC. Outcomes of percutaneous zygapophysial and sacroiliac joint neurotomy in a community setting. Pain Med 2011;12:209-18.

14. Dreyfuss P, Halbrook B, Pauza K, et al. Efficacy and validity of radiofrequency neurotomy for chronic lumbar zygapophysial joint pain. Spine 2000;25:1270-7.

15. Masala S, Nano G, Mammucari M, et al. Medial branch neurotomy in low back pain. Neuroradiology 2012;54:737-44.

16. Tekin I, Mirzai H, Ok G, et al. A comparison of conventional and pulsed radiofrequency denervation in the treatment of chronic facet joint pain. Clin J Pain 2007;23:524-9.

17. Kroll HR, Kim D, Danic MJ, et al. A randomized, double-blind, prospective study comparing the efficacy of continuous versus pulsed radiofrequency in the treatment of lumbar facet syndrome. J Clin Anesth 2008;20:534-7.

18. Streitberger K, Müller T, Eichenberger U, et al. Factors determining the success of radiofrequency denervation in lumbar facet joint pain: a prospective study. Eur Spine J 2011;20:2160-5.

19. Mikeladze G, Espinal R, Finnegan R, et al. Pulsed radiofrequency application in treatment of chronic zygapophyseal joint pain. Spine J 2003;3:360-2.

20. Aksu R, U ur F, Bicer C, et al. The efficiency of pulsed radiofrequency application on L5 and 16 dorsal roots in rabbits developing neuropathic pain. Reg Anesth Pain Med 2010;35:11-5. 